\title{
Knowledge, attitudes and practices towards COVID-19 in Saudi Arabia: Planning implications for public health pandemics
}

Mohammed J. Almalki ( $\nabla$ mjalmalki@jazanu.edu.sa )

Jazan University

\section{Research article}

Keywords: Knowledge, attitudes, practices, COVID-19, novel coronavirus disease, SARS-CoV-2, pandemic, preventive measures, health crisis, Saudi Arabia

Posted Date: September 14th, 2020

DOI: https://doi.org/10.21203/rs.3.rs-67654/v1

License: (c) (1) This work is licensed under a Creative Commons Attribution 4.0 International License. Read Full License 


\section{Abstract}

Background

Saudi Arabian authorities have implemented a number of preventive measures to confront COVID-19, including complete public lockdown, limitations on many services and a public awareness campaign. The success of these preventive measures is highly dependent on individuals' compliance, which is influenced by their knowledge, attitudes and practices towards this disease. This study aims to assess the knowledge, attitudes and practices towards COVID-19 among the population of Saudi Arabia.

Methods

This is a cross-sectional design study conducted between May 4 and May 21, 2020, using an online survey of 1135 participants. The survey instrument consisted of demographic characteristics, 19 items on knowledge, 4 items on attitudes and 6 items on practices. Descriptive statistics, independent sample $t$-test, analysis of variance, Mann-Whitney $\mathrm{U}$ test, Kruskal-Wallis test, standard multiple regression analysis and ordinal logistic regression analysis were conducted.

\section{Results}

The majority of the study participants were knowledgeable about COVID-19, with an overall correct rate of $77 \%$. Most participants were worried of contracting COVID-19 (96.3\%), and they held positive attitudes towards the intent to use a vaccine for COVID-19 if it was available (81\%), informing health authorities if they developed symptoms of COVID-19 (98.1\%) and confidence in the government efforts during the COVID-19 pandemic (90\%). Most participants were also taking precautions such as keeping social distancing ( $99.2 \%)$, avoiding leaving the house (98.6\%) and wearing face masks in public (92.2\%). Nearly all of the respondents stated that they were avoiding shaking hands (96.8\%), avoiding touching their face with unwashed hands (96.7\%) and washing/rubbing hands as recommended (96.6\%). Male participants with higher education level and high income who had attended a health education activity were more likely to have more COVID-19 knowledge.

\section{Conclusions}

The findings of this research suggest that the Saudi population are generally knowledgeable and have good attitudes and practices regarding COVID19. Health authorities in Saudi Arabia may benefit from the findings of this research, as the results could be used to improve planning for COVID-19related efforts and to plan for future health crises. Such planning will help local authorities react promptly to prevent any health threats to the Saudi population and to those who visit Islamic holy places in Saudi Arabia.

\section{Background}

Coronavirus disease 2019 (COVID-19) is an infectious disease caused by severe acute respiratory syndrome coronavirus 2 (SARS-CoV-2). This disease emerged in Wuhan, China, late December 2019, and spread quickly around the world [1]. Recent statistics indicate that the number of people who have been infected with the novel coronavirus worldwide is 14,562,550, with 607,781 confirmed deaths as of July 21, 2020 [2].

Due to the disease's rapid worldwide spread, in January 2020, the World Health Organization (WHO) announced that the COVID-19 outbreak was a global public health pandemic [3, 4]. This disease creates high pressure on global healthcare systems. Many people infected with COVID-19 develop acute respiratory distress syndrome, requiring intensive care unit (ICU) services. Several healthcare systems around the world have struggled to meet these needs, as their ICU beds are limited. Many businesses around the world, including those of the food, commercial and health material supply chains, have been disrupted by COVID-19. Many countries have reported a lack of medical materials and equipment as strict measures are applied to the international trade, travel and import of materials $[5,6]$. The WHO indicated that the shortage of personal protective equipment is one of the most urgent threats to the collective ability to save lives during the COVID-19 pandemic [3].

In Saudi Arabia, the prevention of, treatment of and research on COVID-19 is a priority health issue [7]. The Saudi government has applied strict public health measures to protect the nation from COVID-19. These measures include banning travel to or from China, closing borders, suspending use of the national cards for travel between Gulf Cooperation Council countries and suspending visas and visits to Saudi Arabia, including for Umrah pilgrimage [8-10]. The government ordered a lockdown of Qatif, the first city in which a case of COVID-19 was confirmed in Saudi Arabia. Later, the government closed holy cities, mosques, schools, universities and public departments and ordered people to stay at home for two weeks. All work was to be performed from homes, except for security, health, and remote support departments. In addition, authorities suspended flights and public transportation for 14 days. A complete public lockdown was then applied to the whole country for 21 days. Authorities closed all shopping malls, in-service restaurants, coffee shops, public parks, public and private recreational establishments and all other services. Exceptions were given to pharmacies and supermarkets. All gathering activities were banded. On March 30, 2020, King Salman ordered all health departments to provide free health services for all patients with confirmed cases and their contacts, whether they were Saudis or not, including both legal or illegal residents [11, 12]. On March 2, 2020, Saudi Arabia recorded the first confirmed case of COVID-19. Despite the unprecedented COVID-19 control measures that have been taken by the government, the number of confirmed cases is currently increasing. As of July 21, 2020, the number of confirmed cases in Saudi Arabia is 253,349 , with 2523 deaths [2]. 
To successfully control COVID-19, people must adhere to the public health preventive measures. The adherence behavior of a population is largely affected by their knowledge, attitudes and practices (KAP) towards a disease [13]. According to KAP theory, "the changes of human behavior are divided into three successive processes: the acquisition of knowledge, the generation of attitudes and the formation of behavior. ... Knowledge is the foundation of behavior change, and belief and attitudes are the driving force of behavior change." [14]. Studying the population KAP towards COVID-19 will help in understanding the current situation and in directing resources and measures of the health sector to the right areas. Lessons learned from this pandemic may improve the planning for and management of future public health crises.

This study aims to assess the KAP towards COVID-19 among the population of Saudi Arabia and to reflect on the efforts implemented by authorities to manage the crisis.

\section{Methods \\ Design and sample}

This study applied a cross-sectional design to assess the KAP of the Saudi Arabian population towards COVID-19. An online survey was conducted from May 4 to May 21, 2020. All citizens and residents of Saudi Arabia who lived in the country during the COVID-19 pandemic and who were aged 18 years or older were eligible to participate in the study.

The protocol of this study was approved by the Research Ethics Committee of Jazan University, Saudi Arabia (REC41/5/095). Participants were provided with all required information about the voluntary nature of their participation in the study, confidentiality measures applied to protect the collected data, and instructions on how to complete the online survey. Although the participation was anonymous, an informed consent of willingness to participate voluntarily was obtained through a yes-no question. Based on the answer, participants were directed to complete the survey or to stop at that point.

\section{Questionnaire}

This questionnaire was developed by the author and consisted of two parts: demographics and KAP. Demographic variables included gender, age, marital status, education, occupation, income per month, place of residence, nationality, source of information and whether the participant had attended a health education activity. The KAP questions were developed based on information published by the WHO, the Ministry of Health (MOH) in Saudi Arabia, the Saudi Centre for Disease Prevention and Control, and the United States Centers for Disease Control and Prevention (CDC). The questionnaire had 29 items: 19 for knowledge (Table 2), 4 for attitudes (Table 5), and 6 for practices (Table 8). Knowledge questions 1-9 were answered with 'yes', 'no' or 'not sure'. Knowledge questions 10-19 were answered by choosing the appropriate answer/answers. Each correct answer carried 1 point and incorrect or 'I do not know' answer carried 0 points. This gave a score range of $0-40$, with a higher score indicating a better knowledge of COVID-19. Attitudes towards COVID-19 were measured through four questions using an ordinal five-point Likert scale. The possible answers were 'strongly agree', 'agree', 'not sure', 'disagree' and 'strongly disagree'. The practices of respondents regarding COVID-19 were assessed using six yes-no questions concerning their behaviours during the pandemic (KAP Questionnaire of COVID-19 in Additional file 1).

Before the distribution of the survey, the questionnaire was reviewed by two public health specialists. Based on this review, modifications of the number and content of questions were made. An Arabic version of the questionnaire was developed by the author, and its clarity was ensured by two bilingual researchers. A pilot study of 15 individuals was carried out to ascertain the clarity and applicability of the study tool and to identify the obstacles and problems that may be encountered during data collection. Based on the findings obtained in the pilot study, some modifications were made, including rewriting two questions to improve clarity.The Cronbach's alpha coefficient of the knowledge questionnaire in this study was .83, indicating reliable internal consistency [15]. For the attitude and practice questions, the inter-item correlations were .3 and .2, respectively. The optimal mean inter-item correlation values range from .2 to $.4[15]$.

\section{Statistical analysis}

For analysis of data, IBM SPSS statistics software, version 26, was used. Initially, data were entered, cleaned up, coded and tested for normality. Frequencies and descriptive statistics of KAP of participants were calculated. Knowledge scores were compared across demographics using the independent samples $t$-test and one-way between-groups analysis of variance (ANOVA). Multiple regression was used to identify factors associated with knowledge scores, considering the demographics as a set of independent variables. For attitudes and practice questions, the Mann-Whitney $U$ and Kruskal-Wallis tests were used to compare the demographics. Ordinal logistic regression analysis was used to identify demographic variables (as a set) associated with attitudes. A $p$-value $\leq .05$ (two-tailed) for all tests was considered statistically significant.

\section{Results}

A total of 1144 participants responded to the survey questionnaire. However, the final sample consisted of 1135 participants, as nine incomplete or duplicated questionnaires were excluded. The average age was 36.93 years (SD $=10.25$, range $18-77)$. The majority of respondents were males $(843$; 
74.3\%), Saudi (1042; 91.8\%), married (855; 75.2\%), from the southern region (739; 65.1\%) and held a university degree (738; $65 \%)$ with a non-health job $(557 ; 49 \%)$ and used social media as a primary source of COVID-19 information $(706 ; 62.2 \%)$ (Table 1).

Table 1

Demographic characteristics of participants

\section{Knowledge}

The majority of the study participants were knowledgeable about COVID-19. The mean COVID-19 knowledge score was 30.77 (SD = 5.39, range 7-40); thus, the mean percentage score was 77\% (Table 2). An independent samples $t$-test was conducted to compare scores for the categories of gender, marital status, and having attended a health education activity on COVID-19. There were significant differences in scores for these demographics (all $p$ $<$.05), with very small effect sizes (Table 3). A one-way between-groups ANOVA was conducted to explore the impact of age, education level, occupation and income per month on the COVID-19 knowledge scores. There were statistically significant differences in knowledge scores for categories of all demographics, with medium effect sizes for education degree $(r=.07)$ and income per month $(r=.06)$. Post hoc comparisons using the Tukey HSD test indicated that the mean knowledge scores for those $>40$ years of age were significantly different from other age groups and those with a health-related occupation were significantly different from other occupation groups, and that the knowledge scores for all education level groups as well as income groups were significantly different from each other (Table 3).

Table 2

Questionnaire items of knowledge regarding COVID-19

Table 3

Knowledge by demographic variables using independent sample t-test and ANOVA

Multiple regression analysis was used to estimate the possible effect of the demographic variables as a set on COVID-19 knowledge scores. It was also used to identify the unique contribution of each factor to the prediction of knowledge scores. Taken as a set, the predictors explain $12 \%$ of the variance in knowledge scores. The overall regression model was statistically significant $F(7,1118)=21.56, p<.001, R^{2}=.12$. However, only four variables made statistically significant unique contributions to the equation at $p<.05$ : gender, education level, income per month and having attended a health education activity. The education level had the largest unique contribution (beta $=.174)$, followed by the income per month $($ beta $=.135)($ Table 4$)$.

Table 4

Summary of coefficients for the standard multiple regression of the demographic predictors on the knowledge scores

\section{Attitudes}

The mean COVID-19 attitude score was 18.57 (SD = 1.66, range 8-20) indicating 92.9\% positive attitudes (Table 5). Regarding the 'worrying about COVID-19' question (Attitude1), the majority of respondents (96.3\%) agreed that they were worried about COVID-19. Using Mann-Whitney U and Kruskal-Wallis tests, Attitude1 was statistically significant at $p<.05$ across gender, age, education level, occupation and income per month, with small effect sizes $(r<.3)$ using Cohen criteria [15]. Post hoc Mann-Whitney tests using a Bonferroni-adjusted alpha level of .017 (.05/3) were used to compare all groups in the variables with three categories. The differences were significant in age (between $<30$ years and $>40$ years, $p=.002, r=.122$ ), education level (between General education and Higher education, $p<.001, r=.269$ and between University education and Higher education, $p<.001, r$ $=.194$ ), occupation (between Health-related and Unemployed, $p=.015, r=.101$ ) and income per month (between 10,000 or less and $>10,000$ to 20,000 , $p=.006, r=.086$ and between 10,000 or less and $>20,000, p=.014, r=.096$; Table 6).

Table 5

Questionnaire items of attitudes towards COVID-19

Table 6.

Attitudes towards COVID-19 by demographic variables

Ordinal logistic regression analysis was performed to assess the impact of a number of factors on the likelihood that respondents would report that they were worried about COVID-19. The model contained five independent variables (gender, age, education level, occupation and income per month). The full model containing all predictors was statistically significant, $X^{2}(5, \mathrm{~N}=1135)=44.61, p<.001$, indicating that the model was able to distinguish between respondents who reported and did not report worrying about COVID-19. Only three of the independent variables made a unique statistically significant contribution to the model: gender $(p=.002$, OR $=.65)$, age $(p=.033$, OR $=.77)$ and education level $(p<.001$, OR $=.54)$. These indicated that for a one-unit decrease in each of these variables, the odds of worrying about COVID-19 is increased by .65 , .77 and .54, respectively, given that all of the other variables in the model are held constant (Table 7). 
Summary of results of ordinal logistic regression analysis on factors significantly associated with attitudes towards COVID-19.

Regarding the 'intention to use vaccine for COVID-19 if it was available' (Attitude2), 81\% of respondents agreed to use the vaccine. Using MannWhitney $\mathrm{U}$ and Kruskal-Wallis tests, Attitude2 was statistically significant at $p<.05$ in gender only, with small effect sizes $(r=.07$; Table 6$)$.

The majority of respondents (98.1\%) agreed to 'inform the health authorities if they developed symptoms of COVID-19' (Attitude3). No statistically significant differences were revealed in this attitude item according to demographic variables (Table 6).

Regarding the 'confidence in the government efforts during COVID-19' (Attitude4), 89.8\% of respondents agreed that they had confidence in these efforts. Using Mann-Whitney $U$ and Kruskal-Wallis tests, Attitude4 was statistically significant at $p<.05$ across age, occupation and income per month. Post hoc Mann-Whitney tests using a Bonferroni-adjusted alpha level of $.017(.05 / 3)$ were used to compare all groups in the variables in three categories. The differences were significant in age (between $<30$ years and $>40$ years, $p<.001, r=.138$ ), occupation (between non-Health related and Unemployed, $p=.002, r=.100$ ) and income per month (between $>10,000$ to 20,000 and $>20,000, p=.014, r=.099$; Table 6). Ordinal logistic regression analysis was performed among the variables for which a statistically significant difference in Attitude4 had been shown (age, occupation and income per month) and Attitude4. The full model containing all predictors was statistically significant, $X^{2}(3, \mathrm{~N}=1135)=9.031, p=.029$. Only the age variable made a unique statistically significant contribution to the model $(p=.006, \mathrm{OR}=1.29)$. This indicated that for a one-unit increase in age, the odds of trust in the government efforts is increased by 1.29 , given that all of the other variables in the model are held constant (Table 7$)$.

\section{Practices}

The mean COVID-19 practice score was $5.80(\mathrm{SD}=.603$, range $1-6)$ indicating a $96.7 \%$ rate of positive practices (Table 8$)$. The majority of respondents agreed that they were 'avoiding leaving house' [Practice1] (98.6\%), 'wearing face masks in crowded areas' [Practice2] (92.2\%) and 'avoiding shaking hands' [Practice3] (96.8\%). Nearly all of the respondents agreed that they were 'keeping social distancing' [Practice4] (99.2\%), 'avoiding touching face with unwashed hands' [Practice5] (96.7\%) and 'washing/rubbing hands as recommended' [Practice6] (96.6\%). Mann-Whitney U and Kruskal-Wallis tests at $p \leq .05$ revealed no significant differences in the practices items Practice1, Practice3 and Practice4 across demographic variables of gender, age, marital status, education level, occupation and income per month. A significant difference in Practice2 was revealed in gender $(p=.014)$, with small effect sizes ( $r=.073$; Table 9). For Practice5, statistically significant differences were found at $p<.05$ across age, marital status and occupation, with small effect sizes $(r<.3)$. Post hoc Mann-Whitney tests using a Bonferroni-adjusted alpha level of .017 (.05/3) were used to compare all groups of age and occupation. The difference was significant in age only (between $<30$ years and $>40$ years, $p=.014, r=.096$; Table 9 ). Similarly, for Practice6, there were statistically significant differences at $p<.05$ in occupation only. Post hoc Mann-Whitney tests using a Bonferroni-adjusted alpha level of $.017(.05 / 3)$ were used to compare all groups of age and occupation. With these tests, the differences were no longer statistically significant (Table 9$)$. Based on these findings, there was no need for further regression analysis.

Table 8

Questionnaire items of practice regarding COVID-19

Table 9

Practices regarding COVID-19 by demographic variables

\section{Discussion}

COVID-19 is a major global threat impacting public health, social life, business, investments, political affairs and almost all other aspects of our life. Thus far, no vaccine or medication has been developed to control this infectious pandemic disease. The only effective way to protect the public from COVID-19 is for all to adhere to proper preventive measures. However, these measures are influenced by the KAP towards COVID-19 in the population $[16,17]$. This study has assessed the KAP towards COVID-19 among the population of Saudi Arabia. It also discusses the efforts implemented by authorities to manage the crisis.

Many public health activities have been undertaken by the MOH to increase people's awareness and preventive practices of COVID-19. An important activity is the public awareness campaign through all available channels of information. The participants of this study stated that they receive COVID19-related information from social media (62\%), $\mathrm{MOH}$ mobile messages (60\%), the $\mathrm{MOH}$ website (50\%) and the public news (43\%). Other important activities by the $\mathrm{MOH}$ include producing public health education guides in 25 languages, more than 26 scientific guides for health practitioners, tens of educational videos, more than 45 prevention protocols for all aspects of life and daily public conferences [18-20]. The government authorities also suspended visas to the country and locked down all cities, schools, universities, public transportation, flights, public departments and malls, with exceptions for pharmacies and supermarkets $[8,11,12]$. Holy and public mosques were closed for the first time in the recent history of the nation. These awareness and preventive efforts have resulted in a good level of knowledge regarding COVID-19 among the Saudi population. 
The majority of the participants in this study (77\%) were knowledgeable about COVID-19 in general. Although this finding is lower than that of a COVID19 KAP study in China (90\%) [13], it is similar to other findings from Saudi Arabia (81.6\%) [17] and Malaysia (81.5\%) [21]. Differences in measurement scales limit accurate comparison of knowledge levels across these studies [21].

In this study, the vast majority of the participants correctly answered the knowledge questions. This could be attributed to the characteristics of the study participants; availability of information; modern technologies, such as the Internet and smartphones; and the public health efforts by the government authorities. However, substantial portions of the participants answered a number of knowledge questions incorrectly. For example, $40 \%$ of the participants were not aware of the $\mathrm{MOH}$ self-assessment tool for COVID-19, and $24 \%$ believed that there is licensed vaccine for COVID-19 available. Nearly $30 \%$ of the participants believed that all patients with COVID-19 develop severe symptoms, while only $38.3 \%$ of the participants ranked pregnant women as a group at increased risk for COVID-19. According to a recent study by CDC researchers, pregnant women are at an increased risk compared to non-pregnant women. Pregnant women with COVID-19 are more likely to be hospitalised and admitted to the ICU for mechanical ventilation than non-pregnant women [22, 23]. Although the majority of participants knew that there is no specific medication for COVID-19 (63\%) and that using medical and nursing care with supportive medications can help most patient recover (62\%), there were still large portions who were not aware of this information (37\% and $38 \%$, respectively). This finding is different from prior studies, in which participants indicated higher knowledge on these topics $[13,17]$. More than one-third of the participants were not aware that in patients with more severe COVID-19, the infection may cause pneumonia and acute respiratory distress syndrome. Overall, $66 \%$ of the participants knew that during the COVID-19 pandemic, anyone with fever, cough or shortness of breath must wear a face mask in addition to isolating himself or herself and contacting the MOH hotline. However, $34 \%$ did not know the importance of wearing a face mask. These knowledge areas may require special attention through intensive awareness interventions.

A significant association was found between knowledge scores and the demographics of gender, age, marital status, education level, occupation, income per month and having attended a health education activity. Testing these predictors as a set, only four predictors made significant unique contributions to the participants' knowledge: gender, education level, income per month and having attended a health education activity. Male participants with a higher education level and high income who attended a health education activity were more likely to have more COVID-19 knowledge. This is consistent with prior research, except for the finding on gender $[13,17,21]$. Public health policymakers may benefit from these findings, as they could be used to direct their awareness interventions to suitable population groups.

Regarding attitudes, the majority of participants held positive attitudes towards COVID-19 measures. Although $96 \%$ feel worried about having COVID19 , which is important for promoting preventive behaviors, $89.8 \%$ are confident that the Saudi government measures are sufficient to control the COVID19 pandemic. This level of trust could be attributed to the substantial COVID-19-related preventive measures and actions taken by the government authorities. This finding is similar to those of other studies from Saudi Arabia [17], China [13] and Malaysia [21]. Significant predictors of being worried about COVID-19 in this study were gender, age and education level. Younger, male and less educated participants are more worried about having COVID-19. Concerning the participants' confidence in the government efforts, only age (being older) made a significant unique contribution after controlling for all associated predictors. Interestingly, when asked whether they would take a vaccine if available, $19 \%$ either were not sure or disagreed. The reason for this is not clear, but it may be due to misinformation among the public. In contrast to the findings of prior research, this attitude is found to be significantly associated with male participants of this study [24]. Most of the participants stated that they will inform the health authorities if they experience symptoms of COVID-19. Unfortunately, $2 \%$ were still not willing to disclose their symptoms, if developed. This attitude could be attributed to their being worried about isolation time and/or due to their worrying about social stigma related to COVID-19. Social stigma can negatively affect those with diseases and their family, friends, caregivers and even communities [25]. Such attitudes may increase the risk of COVID-19 spreading throughout the population. Hopefully, this attitude will change with time in response to the current intensive public awareness campaign concerning COVID-19.

Most participants of this study reported taking precautions to protect themselves and others from COVID-19. Nearly all participants reported that they maintain social distancing $(99.2 \%)$ and avoid leaving the house except for necessities $(98.6 \%)$. These practices reflect their desire to prevent this infectious disease. Interestingly, $92 \%$ of the participants indicated that they wear a face mask in public. This could be attributed to the good understanding of the high infectiousness of COVID-19 and their ability to afford the cost of face masks. At the time of data collection, the MOH and WHO urged people not to use face masks, except for those with respiratory symptoms or who were caring for COVID-19 patients [26, 27]. The WHO had stated that using face masks by healthy people to prevent COVID-19 may create a false sense of security, result in unnecessary costs, and take masks away from healthcare workers who need them most [26]. It is possible that the $8 \%$ of respondents who did not wear face masks in public were following the previous instruction by the $\mathrm{MOH}$ and the WHO. Currently, wearing a face mask in public is mandatory, as the authorities of Saudi Arabia imposed financial fines on those who do not comply [28]. A significant association at $p<.05$ was found between wearing a face mask in public and gender, as females showed more commitment. One of the unexpected results is that $97 \%$ of the participants avoid shaking hands. Prior research reported a lower percentage among the Saudi population [17]. Shaking hands is a crucial public practice in Saudi Arabia that is seen as a sign of respect. Avoiding shaking hands during this pandemic is a major behavioral development that indicates public seriousness in dealing with COVID-19. The results also indicate that $97 \%$ of the participants maintained proper hand hygiene (according to the recommendations) and only touched their faces with clean hands. This finding is higher than that of other studies [17, 21]. Avoiding of touching the face with unwashed hands was found to be significantly associated with age (being older).

Generally, the good practices of the participants towards COVID-19 could be attributed to the modern life in Saudi Arabia and the major preventive efforts and strict control measures taken by the government during the COVID-19 pandemic. 


\section{Recommendations to the health system}

Public health as a discipline in Saudi Arabia has faced many challenges over the past decades, as most support is directed to clinical medicine. COVID19 has made public health and clinical medicine again work side by side in order to protect the society. This collaboration needs to be strengthened, with more focus on public health, as proposed by the Saudi Vision 2030.

The $\mathrm{MOH}$ has issued a number of health awareness guides in many languages. However, the availability of mobile and social media communications for expatriate workers in Saudi Arabia who are non-Arabic or English speakers appears to be less than supposed. It is necessary to pay attention to this category of workers because they constitute a large segment of the Saudi population.

Participants mentioned that they derive most of their information on COVID-19 from four sources: social media, mobile messages from the MOH, the $\mathrm{MOH}$ website and public news, respectively. It would therefore be appropriate to use these methods in future awareness campaigns. In addition, it is necessary to gather all COVID-19 efforts by various parties in a single website. This step will make it easier for researchers, planners and those interested to follow the latest developments and measures of the pandemic.

The enactment of laws and regulations to control COVID-19, along with focused awareness campaigns, have shown positive results regarding the level of knowledge and people's attitudes and practices. In support of awareness campaigns during future epidemic outbreaks, health authorities may need to impose supportive laws and regulations to encourage people to adhere to preventive measures.

Drawing on its considerable experience during COVID-19, the $\mathrm{MOH}$, in collaboration with other bodies, should develop a comprehensive control system to manage emerging health epidemics. Health leaders and managers at all levels must be trained to lead during health pandemics and crises.

\section{Study Strengths And Limitations}

This study has a number of limitations. Due to the limited time and the urgency of the pandemic, the study used a convenience sampling method. The data were collected from participants who were willing to participate in the study. Although all regions of Saudi Arabia were included, the voluntary sampling methodology and variance in the number of participants may limit the ability to generalise the findings to the Saudi population. In addition, the study used an online survey to collect the data, leaving the interpretation to the participants. Participants may also have given socially acceptable responses, rather than their real attitudes and practices. A further limitation of the present study is that it focuses on educated people who have internet access. Vulnerable populations of Saudi Arabia, such as rural communities, older people, expatriate labor workers and those who cannot read or use technology, need more consideration in future research. Despite these limitations, the findings of the study provide an important contribution to the existing research on the KAP of COVID-19, particularly in Saudi Arabia. The findings could assist healthcare leaders and policymakers in understanding the KAP and experience of the Saudi population regarding COVID-19. This may help health authorities plan for future preventive efforts and health crises.

\section{Conclusion}

The findings of this study suggest that the Saudi population are generally knowledgeable and having good attitudes and practices regarding COVID-19. In particular, male participants with higher education level and high income and who attended a health education activity are more likely to have more COVID-19 knowledge. Saudi Arabia has experience in dealing with epidemiological challenges that emerge at mass gathering activities such as Hajj. In addition to this experience, the findings of this research could be used to develop appropriate strategies to improve COVID-19-related KAP and to plan for future health crises such as pandemics. Such planning will help local authorities react promptly in order to prevent any health threats to the Saudi population and those who visit Islamic holy places in Saudi Arabia.

\section{Abbreviations}

ANOVA: Analysis of Variance; CDC: Centers for Disease Control and Prevention (CDC); COVID-19: Coronavirus disease 2019; ICU: Intensive Care Unit; KAP: Knowledge, Attitudes and Practice; SARS-CoV2: severe acute respiratory syndrome coronavirus 2; WHO: World Health Organization; MOH: Ministry of Health.

\section{Declarations}

\section{Ethics approval and consent to participate}

The Research Ethics Committee of Jazan University, Saudi Arabia approved the study protocol under reference (REC41/5/095). Although the participation is anonymous, an Informed consent of willingness to participate voluntarily was obtained through answering a yes-no question at the beginning of the questionnaire.

\section{Consent for publication}


Not applicable.

\section{Availability of data and materials}

The datasets used and/or analyzed during the current study are available from the corresponding author upon reasonable request.

\section{Competing interests}

The author declares that he has no competing interests.

\section{Funding}

None.

\section{Author Contributions}

Mohammed J. Almalki is the author responsible for conception, design, acquisition of data, or analysis and interpretation of data, drafting the article or revising it critically for important intellectual content, gave final approval of the version to be published, and agreed to be accountable for all aspects of the work.

\section{Acknowledgements}

The author acknowledge with thank Dr. Yasser Hassan for statistical support, Cambridge Proofreading LLC and Maram M. Almalki for English editing, and the respondents for participation in this study.

\section{References}

1. World Health Organization. Coronavirus. 2020. https://www.who.int/emergencies/diseases/novel-coronavirus-2019. Accessed 29 Mar 2020.

2. World Health Organization. Coronavirus disease (COVID-19) situation dashboard. 2020. https://experience.arcgis.com/experience/685d0ace521648f8a5beeeee1b9125cd. Accessed 21 July 2020.

3. World Health Organization. Coronavirus disease (COVID-19) - events as they happen. 2020. https://www.who.int/emergencies/diseases/novelcoronavirus-2019/events-as-they-happen. Accessed 29 Mar 2020.

4. World Health Organization. WHO announces COVID-19 outbreak a pandemic. 2020. https://www.euro.who.int/en/health-topics/healthemergencies/coronavirus-covid-19/news/news/2020/3/who-announces-covid-19-outbreak-a-pandemic. Accessed 29 Mar 2020.

5. Tanne JH, Hayasaki E, Zastrow M, Pulla P, Smith P, Rada AG. Covid-19: how doctors and healthcare systems are tackling coronavirus worldwide. BMJ. 2020;368:m1090. http://doi.org/10.1136/bmj.m1090.

6. Miani A, Burgio, E., Piscitelli, P., Lauro, R., \& Colao, A. The Italian war-like measures to fight coronavirus spreading: Re-open closed hospitals now. Lancet, EClinicalMedicine. 2020;100320. https://doi.org/10.1016/j.eclinm.2020.100320.

7. Ministry of Health. Guideline for health system research samll grant program: Emerging novel coronavirus outbreak. Riyadh: Ministry of Health; 2020.

8. Ebrahim SH, Memish ZA. Saudi Arabia`s measures to curb the COVID-19 outbreak: temporary suspension of the Umrah pilgrimage. J Travel Med. 2020. http://doi.org/10.1093/jtm/taaa029.

9. Ebrahim SH, Ahmed QA, Gozzer E, Schlagenhauf P, Memish ZA. Covid-19 and community mitigation strategies in a pandemic. BMJ. 2020;368:m1066. http://doi.org/10.1136/bmj.m1066.

10. Ahmed QA, Memish ZA. The cancellation of mass gatherings (MGs)? Decision making in the time of COVID-19. Travel Med Infect Dis. 2020:101631. http://doi.org/10.1016/j.tmaid.2020.101631.

11. Ministry of Health. Ministry News - Covid-19. 2020. https://www.moh.gov.sa/Ministry/MediaCenter/News/Pages/default.aspx. Accessed 27 Apr 2020.

12. Saudi Press Agency. Covid-19. 2020. https://www.spa.gov.sa/home.php?lang=ar. Accessed

13. Zhong B-L, Luo W, Li H-M, Zhang Q-Q, Liu X-G, Li W-T, Li Y. Knowledge, attitudes, and practices towards COVID-19 among Chinese residents during the rapid rise period of the COVID-19 outbreak: a quick online cross-sectional survey. International Journal of Biological Sciences. 2020;16(10):1745. http://doi.org/10.7150/ijbs.45221.

14. Fan Y, Zhang S, Li Y, Li Y, Zhang T, Liu W, Jiang H. Development and psychometric testing of the Knowledge, Attitudes and Practices (KAP) questionnaire among student Tuberculosis (TB) Patients (STBP-KAPQ) in China. BMC Infectious Diseases. 2018;18(1):213. 
http://doi.org/10.1186/s12879-018-3122-9.

15. Pallant J. SPSS survival manual: a step by step guide to data analysis using IBM SPSS, Sixth edtition edn. New Yourk: MC Graw Hill Education; 2016.

16. Akalu Y, Ayelign B, Molla MD. Knowledge, attitude and practice towards COVID-19 among chronic disease patients at Addis Zemen Hospital, Northwest Ethiopia. Infection and Drug Resistance. 2020;13:1949-60.

17. Al-Hanawi MK, Angawi K, Alshareef N, Qattan AM, Helmy HZ et al. Knowledge, attitude and practice toward COVID-19 among the public in the Kingdom of Saudi Arabia: a cross-sectional study. Frontiers in Public Health. 2020;8. http://doi.org/10.3389/fpubh.2020.00217.

18. Ministry of Health. Health protocols to limit the spread of the Corona-Covid-19 virus. 2020. https://www.covid19awareness.sa/archives/5460. Accessed 12 July 2020.

19. Ministry of Health. New Coronavirus. 2020. https://www.moh.gov.sa/awarenessplateform/VariousTopics/Pages/COIVD-19.aspx. Accessed 12 July 2020.

20. Ministry of Health. Guides and rules related to coped-19 virus. 2020. https://www.moh.gov.sa/Ministry/MediaCenter/Publications/Pages/covid19.aspx. Accessed 12 July 2020.

21. Azlan AA, Hamzah MR, Sern TJ, Ayub SH, Mohamad E. Public knowledge, attitudes and practices towards COVID-19: A cross-sectional study in Malaysia. Plos one. 2020;15(5):e0233668. http://doi.org/10.1371/journal.pone.0233668.

22. Ellington S, Strid P, Tong VT, Woodworth K, Galang RR, Zambrano LD, Nahabedian J, Anderson K, Gilboa SM. Characteristics of women of reproductive age with laboratory-confirmed SARS-CoV-2 infection by pregnancy status-United States, January 22-June 7, 2020. Journal. 2020;69(25):769. https://www.cdc.gov/mmwr/volumes/69/wr/mm6925a1.htm. Accessed 22 July 2020.

23. Centers for Disease Control and Prevention. Coronavirus disease 2019 (covid-19) - if you are pregnant, breastfeeding, or caring for young children: protect yourself and your family from covid-19. 2020. https://www.cdc.gov/coronavirus/2019-ncov/need-extra-precautions/pregnancybreastfeeding.html. Accessed 12 July 2020.

24. ALdowyan N, Abdallah AS, El-Gharabawy R. Knowledge, attitude and practice (KAP) study about Middle East respiratory syndrome coronavirus (MERS-CoV) among population in Saudi Arabia. International Archives of Medicine. 2017;10(254). http://doi.org/10.3823/2524.

25. World Health Organization. Social stigma associated with COVID-19. 2020. https://www.who.int/docs/default-source/coronaviruse/covid19stigma-guide.pdf. Accessed 19 July 2020.

26. World Health Organization. Advice on the use of masks in the context of COVID-19. 2020. https://apps.who.int/iris/rest/bitstreams/1274280/retrieve. Accessed 19 July 2020.

27. Ministry of Health. Avoid the wrong behaviors to prevent coronavirus. 2020. https://www.moh.gov.sa/awarenessplateform/VariousTopics/Pages/COIVD-19.aspx. Accessed 19 July 2020.

28. Ministry of Interior. Ministry of Interior approves revising regulations on limiting gatherings, updating violations classification schedule. 2020. https://www.moi.gov.sa. Accessed 19 July 2020.

\section{Tables}




\begin{tabular}{|c|c|c|c|}
\hline \multicolumn{4}{|l|}{$\begin{array}{l}\text { Table } 1 \\
\text { Demographic characteristics of participants }\end{array}$} \\
\hline Variables & & $N$ & $\%$ \\
\hline \multirow[t]{2}{*}{ Gender } & Male & 843 & 74.3 \\
\hline & Female & 292 & 25.7 \\
\hline \multirow[t]{3}{*}{ Age } & $<30$ years & 290 & 25.6 \\
\hline & $30-40$ years & 477 & 42.0 \\
\hline & $>40$ years & 368 & 32.4 \\
\hline \multirow[t]{3}{*}{ Marital status } & Married & 853 & 75.2 \\
\hline & Never married & 273 & 24.1 \\
\hline & Others* & 9 & .8 \\
\hline \multirow[t]{2}{*}{ Nationality } & Saudi & 1042 & 91.8 \\
\hline & Non-Saudi & 93 & 8.2 \\
\hline \multirow[t]{3}{*}{ Education level } & General Education & 212 & 18.7 \\
\hline & University Education & 738 & 65.0 \\
\hline & Higher Education & 185 & 16.3 \\
\hline \multirow[t]{3}{*}{ Occupation } & Health related & 196 & 17.3 \\
\hline & Non-health related & 557 & 49.0 \\
\hline & Unemployed & 382 & 33.7 \\
\hline \multirow[t]{3}{*}{ Income per month } & SR 10,000 or less & 525 & 46.3 \\
\hline & > SR 10,000 to 20,000 & 482 & 42.5 \\
\hline & > SR 20,000 & 128 & 11.2 \\
\hline \multirow[t]{2}{*}{ Having attended a health education activity } & No & 638 & 56.2 \\
\hline & Yes & 497 & 43.8 \\
\hline \multirow[t]{5}{*}{ Region } & Central & 117 & 10.3 \\
\hline & Northern & 89 & 7.8 \\
\hline & Southern & 739 & 65.1 \\
\hline & Eastern & 67 & 6.0 \\
\hline & Western & 123 & 10.8 \\
\hline \multirow[t]{8}{*}{ Information sources** } & Social Media & 706 & 62.2 \\
\hline & MOH Mobile Messages & 675 & 59.5 \\
\hline & MOH Website & 570 & 50.2 \\
\hline & Public News & 490 & 43.2 \\
\hline & WHO Website & 343 & 30.2 \\
\hline & Internet Search Engines & 242 & 21.3 \\
\hline & Family & 195 & 17.2 \\
\hline & Others & 13 & 1.1 \\
\hline $\begin{array}{l}\text { Note. * Others in the marital status include } \\
\text { ** Participants can select more than one so }\end{array}$ & Herld Health Oranenize & . & as $G$ \\
\hline
\end{tabular}


Table 2

Questionnaire items of knowledge regarding COVID-19

Items

$N=1135$

Yes (\%)

K.1 Have you heard about COVID-19?

1114 (98.1)

$1129 \quad(99.5)$

K.3 Have you heard about the self-assessment tool for COVID-19? 687

(60.5)

$\mathrm{K} .4$

There is a licensed vaccine available for protection from COVID-19.

275

(24.2)

$\mathrm{K} .5$

All cases of COVID-19 develop to severe conditions.

356

(31.4)

K.6

The probability of getting COVID-19 increases in mass gathering.

1101

(97.0)

K.7 Are there any confirmed cases or deaths of COVID-19 in this country (Saudi Arabia).

1096 (96.6)

K.8 It is believed that the primary source of COVID-19 is zoonotic (emerged from an animal source).

828

$(73.0)$

K.9 There are diagnostic tests available for COVID-19.

1034

K.10

Where did COVID-19 appear for the first time? (Wuhan, China).

1077

(94.9)

K.11

Which of the following is the cause of COVID-19? (Virus).

1010 (89.0)

K.12

What is the confirmed incubation period so far for COVID-19 disease? (2-14 days).

1079

K.13

COVID-19 symptoms may include:

1011

K.13b) Dry cough.

994

K.13c) Shortness of breath.

1061

K.13d) Tiredness.

627

K.13e) Sore throat.

725

K.13f) Congested or runny nose.

K.13g) Diarrhea.

404

K.13h) Loss of taste or smell.

K.14 COVID-19 may affect all age groups, but which groups are at increased risk for this disease?

K.14a) Older people.

K.14b) People with pre-existing medical conditions.

K.14c) Pregnant women.

K.15 Is there a specific medication for COVID-19?

K.15a) There is no specific medication.

K.15b) Medical and nursing care with supportive medications can help most patients recover from COVID-19.

706

K.16 In more severe cases of COVID-19, infection can cause:

K.16a) Pneumonia. 436

K.16b) Acute respiratory distress syndrome

K.16c) Death.

907

K.17

People should wear face masks:

K.17a) If they suffer from respiratory symptoms (coughing or sneezing).

1015

(89.4)

Page 11/18 


\begin{tabular}{|c|c|c|c|c|}
\hline & K.17b) & During a direct contact with someone who has respiratory symptoms. & 1040 & $(91.6)$ \\
\hline K.18 & \multicolumn{4}{|c|}{ Anyone during the pandemic of COVID-19 with fever, cough or shortness of breath, must: } \\
\hline & K.18a) & Wear a face mask. & 747 & $(65.8)$ \\
\hline & K.18b) & Isolate himself / herself away from others. & 1039 & $(91.5)$ \\
\hline & K.18c) & Call the Ministry of Health hotline (937). & 1046 & $(92.2)$ \\
\hline & K.18d) & Visit nearest health facility while taking the necessary precautions. & 763 & $(67.2)$ \\
\hline \multirow[t]{7}{*}{ K.19 } & \multicolumn{4}{|c|}{ Which of the following are prevention measures of COVID-19? } \\
\hline & K.19a) & $\begin{array}{l}\text { Wash hands with water and soap for } 40 \text { seconds / rub hands with alcohol-based sanitisers for } 20 \\
\text { seconds. }\end{array}$ & 1100 & $(96.9)$ \\
\hline & K.19b) & Avoiding touching the eyes, nose and mouth with unwashed hands. & 1049 & $(92.4)$ \\
\hline & K.19c) & Avoiding contacts with infected people. & 1042 & $(91.8)$ \\
\hline & K.19d) & Covering mouth and nose when coughing or sneezing. & 1009 & $(88.9)$ \\
\hline & K.19e) & Avoiding shaking hands. & 1037 & $(91.4)$ \\
\hline & K.19f) & Wash hands or using hand sanitiser after touching items in public places. & 922 & $(81.2)$ \\
\hline
\end{tabular}




\begin{tabular}{|c|c|c|c|c|c|c|}
\hline \multicolumn{7}{|c|}{$\begin{array}{l}\text { Table } 3 \\
\text { Knowledge by demographic variables using independent sample t-test and ANOVA }\end{array}$} \\
\hline Variable & No. & Mean & SD & t/F-Value & P-Value & Effect Size \\
\hline \multicolumn{7}{|l|}{ Gender } \\
\hline Male & 843 & 31.06 & 5.28 & 3.09 & .002 & .008 \\
\hline Female & 292 & 29.94 & 5.63 & & & \\
\hline \multicolumn{7}{|l|}{ Age } \\
\hline$<30$ years & 290 & 29.79 & 5.69 & 17.84 & .000 & .022 \\
\hline $30-40$ years & 477 & 30.55 & 5.57 & & & \\
\hline$>40$ years & 368 & 31.85 & 4.70 & & & \\
\hline \multicolumn{7}{|l|}{ Marital status } \\
\hline Married & 853 & 30.99 & 5.23 & 2.45 & .015 & .005 \\
\hline Never married & 273 & 30.07 & 5.87 & & & \\
\hline \multicolumn{7}{|l|}{ Education level } \\
\hline General Education & 212 & 27.93 & 6.364 & 44.11 & .000 & .072 \\
\hline University Education & 738 & 31.15 & 4.972 & & & \\
\hline Higher Education & 185 & 32.52 & 4.543 & & & \\
\hline \multicolumn{7}{|l|}{ Occupation } \\
\hline Health related & 196 & 32.80 & 4.495 & 19.49 & .000 & .030 \\
\hline Non-health related & 557 & 30.66 & 5.272 & & & \\
\hline Unemployed & 382 & 29.91 & 5.717 & & & \\
\hline \multicolumn{7}{|l|}{ Income per month } \\
\hline SR 10,000 or less & 525 & 29.37 & 5.946 & 39.06 & .000 & .065 \\
\hline > SR 10,000 to 20,000 & 482 & 31.68 & 4.666 & & & \\
\hline$>$ SR 20,000 & 128 & 33.12 & 3.789 & & & \\
\hline \multicolumn{7}{|c|}{ Having attended a health education activity } \\
\hline No & 638 & 29.93 & 5.61 & -6.18 & .000 & .032 \\
\hline Yes & 797 & 31.86 & 4.88 & & & \\
\hline
\end{tabular}

\section{Table 4}

Summary of coefficients for the standard multiple regression of the demographic predictors on the knowledge scores

\begin{tabular}{|c|c|c|c|c|c|c|}
\hline \multirow{2}{*}{\multicolumn{2}{|c|}{$\begin{array}{l}\text { Model } \\
\text { Variable }\end{array}$}} & \multicolumn{2}{|c|}{ Unstandardised Coefficients } & \multirow{2}{*}{$\begin{array}{l}\text { Standardised Coefficients } \\
\text { Beta }(\beta)\end{array}$} & \multirow[t]{2}{*}{$\mathrm{t}$} & \multirow[t]{2}{*}{ Sig. } \\
\hline & & $\mathrm{B}$ & Std. Error (SE) & & & \\
\hline \multirow[t]{5}{*}{1} & (Constant) & 25.225 & 1.298 & & 24.888 & $<.001$ \\
\hline & Gender & -.745 & .374 & $-.060 *$ & -1.994 & $<.046$ \\
\hline & Education level & 1.587 & .288 & $.174 * \star$ & 5.503 & $<.001$ \\
\hline & Income per month & 1.080 & .293 & $.135^{\star *}$ & 3.683 & $<.001$ \\
\hline & Having attended a health education activity & 1.399 & .327 & $.129 * *$ & 4.277 & $<.001$ \\
\hline
\end{tabular}

Note. Dependent variable is knowledge scores. Only significant coefficients are presented in this table. ${ }^{*} p<.05 .{ }^{\star *} p<.001 . \mathrm{R}^{2}=.119\left(\right.$ Adjusted $\mathrm{R}^{2}=$ .113). 


\begin{tabular}{|c|c|c|c|c|c|c|c|}
\hline & & $n$ & $(\%)$ & $n$ & $(\%)$ & $n$ & $(\%)$ \\
\hline $\begin{array}{l}\text { Attitude } 1 \\
\text { (A.1) }\end{array}$ & I am worried about myself or a family member being infected. & 1093 & $(96.3)$ & 32 & $(2.8)$ & 10 & $(.9)$ \\
\hline $\begin{array}{l}\text { Attitude2 } \\
\text { (A.2) }\end{array}$ & If a vaccine is available, I will take it. & 919 & $(81.0)$ & 179 & $(15.8)$ & 37 & (3.3) \\
\hline $\begin{array}{l}\text { Attitude3 } \\
\text { (A.3) }\end{array}$ & If I developed symptoms of COVID-19, I will inform the health authority. & 1114 & $(98.1)$ & 19 & $(1.7)$ & 2 & $(.2)$ \\
\hline $\begin{array}{l}\text { Attitude4 } \\
\text { (A.4) }\end{array}$ & $\begin{array}{l}\text { I am confident that the current protection measures taken by the government are } \\
\text { sufficient to control the disease. }\end{array}$ & 1019 & $(89.8)$ & 99 & (8.7) & 17 & (1.5) \\
\hline
\end{tabular}

Note. $N=$ the total number of the sample; answer options= Agree (Agree \& Agree Strongly), Not Sure, and Disagree (Disagree and Strongly Disagree); $n=$ number of respondents to each item; $\%$ = percentage of the answers to each item compared to the total sample. 
Table 6.

Attitudes towards COVID-19 by demographic variables

Attitude items

\begin{tabular}{|c|c|c|c|c|c|c|c|c|c|c|c|}
\hline \multirow[t]{2}{*}{$\begin{array}{l}\text { Independent } \\
\text { variables }\end{array}$} & \multirow[t]{2}{*}{$n$} & \multicolumn{2}{|l|}{$\begin{array}{l}\text { A.1 Worrying about } \\
\text { COVID-19 }\end{array}$} & \multicolumn{3}{|c|}{ A. 2 Intention to use vaccine } & \multicolumn{3}{|c|}{$\begin{array}{l}\text { A.3 Intention to report } \\
\text { symptoms }\end{array}$} & \multicolumn{2}{|c|}{$\begin{array}{l}\text { A. } 4 \text { Confidence in the gov } \\
\text { efforts }\end{array}$} \\
\hline & & $\mathrm{Z} / x^{2}(\mathrm{df})$ & $p$ & $\begin{array}{l}\text { Mean } \\
\text { Rank }\end{array}$ & $\begin{array}{l}\mathrm{Z} / \\
x^{2}(\mathrm{df})\end{array}$ & $p$ & $\begin{array}{l}\text { Mean } \\
\text { Rank }\end{array}$ & $\begin{array}{l}\mathrm{Z} / \\
x^{2}(\mathrm{df})\end{array}$ & $p$ & $\begin{array}{l}\text { Mean } \\
\text { Rank }\end{array}$ & $\begin{array}{l}\mathrm{Z} / \\
x^{2}(\mathrm{df})\end{array}$ \\
\hline
\end{tabular}

Gender

Male

$843 \quad 575.96 \quad-2.079$

$.038^{\star}$

$578.94 \quad-2.213$

536.42

Female

$292 \quad 545.02$

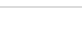

Age

$\begin{array}{lllll}<30 \text { years } \quad 290 \quad 594.43 & 10.470(2) & .005^{\star}\end{array}$

30-40 years $\quad 477 \quad 573.44$

$586.89 \quad 1.831(2) \quad .400$

564.16

$>40$ years

$368 \quad 540.12$

558.09

$564.88 \quad .723(2)$

.697

$515.41 \quad 15.162(2)$

$.001^{\star}$

Marital

status

Married

$853 \quad 559.05 \quad-1.213$

.225

$558.10-1.140$

.254

580.37

572.66

597.04

Never-

$273 \quad 577.40$

580.37

564.41

571.80

married

Education

level

\begin{tabular}{|c|c|c|c|c|c|c|c|c|c|c|c|c|c|}
\hline $\begin{array}{l}\text { General } \\
\text { Education }\end{array}$ & 212 & 602.74 & $43.239(2)$ & $.001 *$ & 568.57 & $2.361(2)$ & .307 & 558.96 & $.866(2)$ & .649 & 588.38 & $2.275(2)$ & .321 \\
\hline $\begin{array}{l}\text { University } \\
\text { Education }\end{array}$ & 738 & 581.89 & & & 575.03 & & & 570.26 & & & 567.78 & & \\
\hline $\begin{array}{l}\text { Higher } \\
\text { Education }\end{array}$ & 185 & 472.76 & & & 539.30 & & & 569.33 & & & 545.52 & & \\
\hline \multicolumn{14}{|l|}{ Occupation } \\
\hline $\begin{array}{l}\text { Health } \\
\text { related }\end{array}$ & 196 & 543.73 & $6.438(2)$ & $.040 *$ & 554.85 & $.716(2)$ & .699 & 574.53 & $.959(2)$ & .619 & 545.99 & $10.739(2)$ & $.005^{\star}$ \\
\hline $\begin{array}{l}\text { Non-health } \\
\text { related }\end{array}$ & 557 & 561.93 & & & 567.29 & & & 563.48 & & & 595.87 & & \\
\hline Unemployed & 382 & 589.30 & & & 575.79 & & & 571.24 & & & 538.65 & & \\
\hline \multicolumn{14}{|l|}{$\begin{array}{l}\text { Income per } \\
\text { month }\end{array}$} \\
\hline $\begin{array}{l}\text { SR } 10,000 \\
\text { or less }\end{array}$ & 525 & 589.55 & $9.798(2)$ & $.007 \star$ & 571.50 & $.266(2)$ & .875 & 562.41 & $5.014(2)$ & .082 & 559.68 & $6.544(2)$ & $.038 *$ \\
\hline $\begin{array}{l}>\text { SR } 10,000 \\
\text { to } 20,000\end{array}$ & 482 & 552.18 & & & 567.01 & & & 579.19 & & & 589.23 & & \\
\hline > SR 20,000 & 128 & 539.21 & & & 557.38 & & & 548.77 & & & 522.19 & & \\
\hline \multicolumn{14}{|l|}{$\begin{array}{l}\text { Having } \\
\text { attended a } \\
\text { health } \\
\text { education } \\
\text { activity }\end{array}$} \\
\hline No & 638 & 573.25 & -.914 & .361 & 568.68 & -.092 & .927 & 569.28 & -.311 & .755 & 578.43 & -1.409 & .159 \\
\hline Yes & 497 & 561.26 & & & 567.13 & & & 566.35 & & & 554.61 & & \\
\hline
\end{tabular}

Note. P-value <.05 is statistically significant; Mann-Whitney U Test for two categorical independent variables; Kruskal-Wallis Test for three or more categorical independent variable; $n=$ the number of respondents in each group; effect size was calculated using eta squared, post-hoc tests and Bonferroni adjustment as appropriate and presented in the result section; for more information on Attitude1 (A.1) - Attitude4 (A.4), see Table 5. 
Table 7

Summary of results of ordinal logistic regression analysis on factors significantly associated with attitudes towards COVID-19.

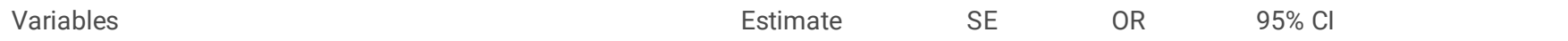

Attitude1: Worrying about COVID-19

$\begin{array}{lllllll}\text { Gender } & -.427^{\star} & .187 & .65 & -.794 & -.061 & .022 \\ \text { Age } & -.262^{\star} & .123 & .77 & -.503 & -.022 & .033 \\ \text { Education level } & -.620^{\star *} & .147 & .54 & -.909 & -.331 \\ \text { Attitude4: Confidence in the government efforts } & & & & & \\ \text { Age } & .251 & .001 & \\ \end{array}$

Note. Dependent variable is worrying about COVID-19. Only significant coefficients are presented in this table. ${ }^{\star} p<.05 .{ }^{*} p<.001$. SE $=$ Std. Error. $\mathrm{OR}=$ Odds Ratio. $\mathrm{Cl}=$ Confidence Interval.

Table 8

Questionnaire items of practice regarding COVID-19

\begin{tabular}{|c|c|c|c|c|c|}
\hline & \multirow[t]{2}{*}{$(N=1135)$} & \multicolumn{2}{|l|}{ Yes } & \multicolumn{2}{|l|}{ No } \\
\hline & & $n$ & $(\%)$ & $n$ & $(\%)$ \\
\hline $\begin{array}{l}\text { Pracitce1 } \\
\text { (P.1) }\end{array}$ & I avoid leaving the house except for necessity. & 1119 & $(98.6)$ & 16 & $(1.4)$ \\
\hline $\begin{array}{l}\text { Practice2 } \\
\text { (P.2) }\end{array}$ & I wear a face mask in crowded places. & 1047 & $(92.2)$ & 88 & $(7.8)$ \\
\hline $\begin{array}{l}\text { Practice3 } \\
\text { (P.3) }\end{array}$ & I avoid touching or shaking hands of others. & 1099 & $(96.8)$ & 36 & $(3.2)$ \\
\hline $\begin{array}{l}\text { Practice4 } \\
\text { (P.4) }\end{array}$ & I am doing my best to keep social distancing. & 1126 & $(99.2)$ & 9 & $(.8)$ \\
\hline $\begin{array}{l}\text { Practice5 } \\
\text { (P.5) }\end{array}$ & I do not touch my mouth, nose or eyes with unwashed hands. & 1097 & $(96.7)$ & 38 & (3.3) \\
\hline $\begin{array}{l}\text { Practice6 } \\
\text { (P.6) }\end{array}$ & $\begin{array}{l}\text { I wash my hands with soap and water for } 40 \text { seconds/ I rub my hands with alcohol-based sanitisers } \\
\text { for } 20 \text { seconds. }\end{array}$ & 1096 & $(96.6)$ & 39 & (3.4) \\
\hline
\end{tabular}

Note. $N=$ the total number of the sample; answer options = yes, no; $n=$ number of respondents to each item; $\%=$ percentage of the answers to each item compared to the total sample. 


\begin{tabular}{|c|c|c|c|c|c|c|c|c|c|c|}
\hline \multicolumn{11}{|c|}{$\begin{array}{l}\text { Table } 9 \\
\text { Practices regarding COVID-19 by demographic variables }\end{array}$} \\
\hline \multirow[t]{2}{*}{ Independent variables } & \multirow[t]{2}{*}{$n$} & \multicolumn{3}{|c|}{ P.1 Avoid leaving house } & \multicolumn{3}{|c|}{$\begin{array}{l}\text { P.2 Wearing a face mask in crowded } \\
\text { places }\end{array}$} & \multicolumn{3}{|c|}{ P.3 Avoiding shaking hands } \\
\hline & & $\begin{array}{l}\text { Mean } \\
\text { Rank }\end{array}$ & $\begin{array}{l}\mathrm{Z} / \\
x^{2}(\mathrm{df})\end{array}$ & $p$ & Mean Rank & $\mathrm{Z} / x^{2}(\mathrm{df})$ & $p$ & $\begin{array}{l}\text { Mean } \\
\text { Rank }\end{array}$ & $\begin{array}{l}\mathrm{Z} / \\
x^{2}(\mathrm{df})\end{array}$ & $p$ \\
\hline \multicolumn{11}{|l|}{ Gender } \\
\hline Male & 843 & 565.90 & -1.794 & .073 & 561.51 & -2.446 & $.014^{\star}$ & 565.80 & -1.263 & .207 \\
\hline Female & 292 & 574.06 & & & 586.73 & & & 574.34 & & \\
\hline \multicolumn{11}{|l|}{ Age } \\
\hline$<30$ years & 290 & 568.17 & $.020(2)$ & .990 & 563.08 & $1.204(2)$ & .548 & 566.43 & $.371(2)$ & .831 \\
\hline $30-40$ years & 477 & 567.67 & & & 565.60 & & & 566.96 & & \\
\hline$>40$ years & 368 & 568.29 & & & 574.99 & & & 570.58 & & \\
\hline \multicolumn{11}{|l|}{ Marital status } \\
\hline Married & 853 & 564.24 & -.658 & .510 & 563.44 & -.024 & .981 & 564.34 & -.502 & .615 \\
\hline Never-married & 273 & 561.19 & & & 563.69 & & & 560.88 & & \\
\hline \multicolumn{11}{|l|}{ Education level } \\
\hline General Education & 212 & 573.32 & $2.141(2)$ & .343 & 579.88 & $3.741(2)$ & .154 & 567.26 & $.737(2)$ & .692 \\
\hline University Education & 738 & 566.00 & & & 568.94 & & & 566.78 & & \\
\hline Higher Education & 185 & 569.86 & & & 550.65 & & & 573.73 & & \\
\hline \multicolumn{11}{|l|}{ Occupation } \\
\hline Health related & 196 & 567.31 & $.954(2)$ & .621 & 574.36 & $.804(2)$ & .669 & 571.52 & $319(2)$ & .853 \\
\hline Non-health related & 557 & 569.89 & & & 564.11 & & & 567.66 & & \\
\hline Unemployed & 382 & 565.60 & & & 570.40 & & & 566.69 & & \\
\hline \multicolumn{11}{|l|}{ Income per month } \\
\hline SR 10,000 or less & 525 & 570.60 & $1.536(2)$ & .464 & 574.17 & $2.957(2)$ & .228 & 568.70 & $.510(2)$ & .775 \\
\hline$>$ SR 10,000 to 20,000 & 482 & 565.40 & & & 559.02 & & & 565.98 & & \\
\hline$>$ SR 20,000 & 128 & 567.13 & & & 576.53 & & & 572.70 & & \\
\hline \multicolumn{11}{|c|}{$\begin{array}{l}\text { Having attended a health education } \\
\text { activity }\end{array}$} \\
\hline No & 638 & 566.22 & -1.018 & .309 & 569.30 & -.328 & .743 & 566.43 & -.602 & .547 \\
\hline Yes & 497 & 570.29 & & & 566.33 & & & 570.01 & & \\
\hline
\end{tabular}


Table 9

Practices regarding COVID-19 by demographic variables (continued)

Independent variables $\quad n \quad$ P.4 Keeping social distancing unwashed hands

P.6 Washing/rubbing hands as

Mean $z /$ Mean Rank

Rank $\quad x^{2}(\mathrm{df})$

Mean Rank

$\mathrm{Z} / \mathrm{x}^{2}(\mathrm{df}) \quad p$ recommended

\begin{tabular}{|c|c|c|c|c|c|c|c|c|c|c|}
\hline & & $\begin{array}{l}\text { Mean } \\
\text { Rank }\end{array}$ & $x^{2}(\mathrm{df})$ & $p$ & Mean Rank & $\mathrm{Z} / x^{2}(\mathrm{df})$ & $p$ & Mean Rank & $\mathrm{Z} / x^{2}(\mathrm{df})$ & $p$ \\
\hline \multicolumn{11}{|l|}{ Gender } \\
\hline Male & 843 & 567.79 & -.241 & .809 & 566.80 & -.670 & .503 & 567.30 & -.385 & .700 \\
\hline Female & 292 & 568.61 & & & 571.45 & & & 570.01 & & \\
\hline \multicolumn{11}{|l|}{ Age } \\
\hline$<30$ years & 290 & 568.59 & $.725(2)$ & .696 & 553.73 & 7.797(2) & $.020 *$ & 558.15 & $3.842(2)$ & .146 \\
\hline $30-40$ years & 477 & 566.55 & & & 571.53 & & & 569.65 & & \\
\hline$>40$ years & 368 & 569.42 & & & 574.66 & & & 573.62 & & \\
\hline \multicolumn{11}{|l|}{ Marital status } \\
\hline Married & 853 & 563.38 & -.142 & .887 & 569.30 & -3.382 & $.001^{\star}$ & 566.00 & $-1.458-$ & .145 \\
\hline Never-married & 273 & 563.88 & & & 545.38 & & & 555.69 & & \\
\hline \multicolumn{11}{|l|}{ Education level } \\
\hline General Education & 212 & 569.82 & $2.549(2)$ & .280 & 568.26 & $.309(2)$ & .857 & 566.08 & $.099(2)$ & .952 \\
\hline University Education & 738 & 566.35 & & & 567.01 & & & 568.28 & & \\
\hline Higher Education & 185 & 572.50 & & & 571.66 & & & 569.09 & & \\
\hline \multicolumn{11}{|l|}{ Occupation } \\
\hline Health related & 196 & 569.60 & $552(2)$ & .759 & 578.31 & $8.645(2)$ & $.013^{\star}$ & 578.81 & $7.956(2)$ & $.019 *$ \\
\hline Non-health related & 557 & 568.42 & & & 572.74 & & & 572.22 & & \\
\hline Unemployed & 382 & 566.56 & & & 555.80 & & & 556.30 & & \\
\hline \multicolumn{11}{|l|}{ Income per month } \\
\hline SR 10,000 or less & 525 & 569.26 & $.693(2)$ & .707 & 565.38 & $1.099(2)$ &. .577 & 562.64 & $2.749(2)$ & .253 \\
\hline$>$ SR 10,000 to 20,000 & 482 & 566.61 & & & 571.69 & & & 573.37 & & \\
\hline$>$ SR 20,000 & 128 & 568.07 & & & 564.83 & & & 569.77 & & \\
\hline \multicolumn{11}{|c|}{$\begin{array}{l}\text { Having attended a health } \\
\text { education activity }\end{array}$} \\
\hline No & 638 & 568.05 & -.040 & .968 & 564.76 & -1.210 & .226 & 567.04 & -.354 & .724 \\
\hline Yes & 497 & 567.93 & & & 572.16 & & & 569.23 & & \\
\hline
\end{tabular}

Note. P-value <.05 is statistically significant; Mann-Whitney U Test for two categorical independent variables; Kruskal-Wallis Test for three or more categorical independent variable; $n=$ the number of respondents in each group; effect size was calculated using eta squared, post-hoc tests and Bonferroni adjustment as appropriate and presented in the result section; for more information on Practice1(P.1) - Practice 6 (P.6), see Table 8.

\section{Supplementary Files}

This is a list of supplementary files associated with this preprint. Click to download.

- Additionalfile1.pdf 